\title{
Effects of Salvia Officinalis Extract on the Breast Cancer Cell Line
}

\author{
Habibeh Zare $\mathrm{a}^{*}$ \\ a Department of Biology, Faculty of Science, Payame-Noor University, P.O. Box 19395-3697, Tehran, Iran.
}

Received 03 January 2019; Accepted 27 February 2019

\begin{abstract}
Background: Common sage (Salvia officinalis L., Lamiaceae) is an aromatic and medicinal plant well known for its antioxidant properties. This plant belongs to Lamiaceae family and has many pharmaceutical properties. Some in vivo studies have shown the biological antioxidant effects of sage. As a member of Salvia officinalis Labiatae, sage is also known as "Maryam flower" in Iran. Sage importance lies in its therapeutic potential. It has been exploited as an antispasmodic, astringent, sedative, anti-hyperglycemic, and anti-inflammatory agent in Iranian medicine. Objective: Studying the anticancer effects of the compounds in Salvia officinalis extracts, such as cineol and camphor. Methods: Cancer was induced by DMBA (dimethyl-benzantheracene) dissolved in sunflower oil for 4 weeks. The case group was treated with sage leaf hydroalcoholic extract for 4 weeks; while the controls received distilled water. Result: Angiogenesis is a key process in cancer spread and metastasis. The hydroalcoholic extract of garden sage halted angiogenesis in the breast cell line of both human and mouse models; the highest impact was observed in hexane extract. Findings indicated the therapeutic effects of garden sage (i.e. its in vitro anti-angiogenesis activity and anti-migratory properties). Conclusion: Saliva officinalis can potentially prevent breast cancer.
\end{abstract}

Keywords: Salvia Officinalis L.; Cancer Cell Line; Antioxidant Profile; Leaf Extract.

\section{Introduction}

\section{Anti-Tumorigenic Effects of Salvia Officinalis}

Regarding the important role of protease enzymes in various complications including cancer, a possible way to combat such complications is the limited application of inhibitory molecules. Jedina et al. [1] extracted $\beta$ - urosolic from garden sage in 2006 to assess its behavior by means of in-vitro protease activity assay on serine protease (trypsin, urokinase) and cysteine protease. Their results indicated the inhibitory impact of $\beta$ - urosolic acid on all the tested proteases in micro molar concentrations.

In 2010, Hadri et al. [2] investigated the toxicity of garden sage essence on the cancerous cell lines. They extracted the essence through aqueous distillation, and its components were separated using column chromatography. The resulting essence and components were analyzed by gas chromatography.

Toxicity of garden sage essence was not evaluated on breast cancer cell line MCF-7, colon cell line HCT-116 and mouse macrophage RAM 264.

$\alpha$-Humulen content of garden sage essence exhibited the highest toxicity on RAM 264.1 and HCT-116. This research confirms the anti-tumorigenic effect of trans- coryophy, llenehumuler extracted from garden sage.

\footnotetext{
* Corresponding author: habibehzare1354@gmail.com

doi http://dx.doi.org/10.28991/SciMedJ-2019-0101-4
}

$>$ This is an open access article under the CC-BY license (https://creativecommons.org/licenses/by/4.0/).

(C) Authors retain all copyrights. 
Garden sage essence compounds included monotropins like $\beta$-pinene, thujone, and cineol which showed increased vital effects on UMSCC1 cells at low concentrations. The acquired IC(50) was $80 \mathrm{mg} / \mathrm{ml}$.

\section{Materials and Methods}

\subsection{Leaves}

40 grams of the aqueous extract was obtained from 200 grams of garden sage. Acute toxicity of the alcoholic extract of garden sage leaf was determined according to the method reported by Bradely [3].

The dosages of garden sage aqueous extract were adjusted to human weighing $59 \mathrm{~kg}$, and finally, $3 \mathrm{mg} / \mathrm{kg}$ was selected.

\subsection{Carcinogen Preparation}

Dimethyl-benzanthracene (DMBA) was used to induce breast cancer in rats.

DMBA is a synthetic polycyclic aromatic hydrocarbon which is, in fact, an in-vitro carcinogen [4].

Numerous studies have reported $20 \mathrm{mg} / \mathrm{ml}$ DMBA can properly induce cancer [5].

DMBA was fed to animals three times a week for one month at the dosage of $10 \mathrm{mg} / \mathrm{ml}$.

\subsection{Garden Sage Preparation}

Salvia officinalis seeds were purchased from Maxima Company. Following cultivation in the greenhouse, its aerial parts including leaves were utilized. The plant extract was prepared using liquid nitrogen and delivered to medical sciences animal room in as a Hydro-alcoholic solution.

\subsection{Antioxidant Activity Measurement folin - ciocalteu reagent}

To measure the total phenolic content, the folin-ciocalteu reagent method, developed by Viado-Martos et al. [6], was employed. In this method, tannic acid was used as a standard. After plotting the calibration curve and determining the linear equation, the total phenolic content amount was expressed as mg tannic acid per liter of sample. To assess the anti-oxidant characteristic of the essence using DPPH strategy (the method developed by Ebrahim Abadi et al. [7]), betacarotene/linoleic acid bleaching [8] and reduction potential [9] methods were implemented. The anti-oxidant activity was represented as IC 50 which indicates the required concentration of the essence to inhibit $50 \%$ of DPPH free radicals. In the case of beta-carotene methodology, IC50 refers to the essence concentration capable of 50\% prevention of betacarotene/linoleic acid emulsion bleaching. Concerning the reduction potential, IC50 can be defined as the sample concentration at which the absorbance equals to 5.0. The AOCS standard method [10] was also employed to determine the amount of peroxide in oil samples packed by HPMC films.

\subsection{Laboratory Rats}

Female Wistar rats were acquired from Bushehr Medical Sciences Animal Department. Animals were kept in the animal room under controlled conditions involving 16:8 light and darkness cycles and temperature of $25^{\circ} \mathrm{C}$.

\subsection{Animal Classification}

54 mature female rats were divided into 4 groups. The control group consisted of 8 rats, which received 3 ml of sunflower oil in two hours, every two days, for three consecutive weeks.

The case group included 20 cancerous rats which orally received aqueous garden sage extract, every day.

Rats were treated for 6 months and analyzed regarding their cancer stage (creation and progression).

The treatment group also encompassed 20 cancerous rats which only received distilled water on a daily basis.

\subsection{Statistical Analysis}

All the experiments were performed with three replications. The obtained data were reported as mean plus standard deviation.

\section{Results}

The results were analyzed by SAS-2000 software (edition 9) using a factorial experiment based on a completely randomized design, and the least significant difference (LSD) mean comparison method at the probability level of $95 \%$. 


\subsection{Findings}

\section{A) Total Phenolic Content and Anti-oxidant Activity}

Garden sage essence encompassed the total phenolic content of 5.276 milligrams of tannic acid per liter of sample. Its anti-oxidant activity is displayed in Table 1 based on IC50, through the implementation of DPPH free radical inhibition method, beta-carotene/linoleic acid emulsion bleaching prevention, and reduction potential, all of which were spectrophotometrically measured.

Lower IC50 indicates higher antioxidant activity of the essence. In all the models, the lowest IC50 belonged to BHT. Here, the necessary amount of garden sage to cause 50\% inhibitory effect is higher in comparison with that of BHT, which implies higher BHT potential $(\mathrm{p}<0.005)$.

Table 1. Anti-oxidant activity (IC50 $\pm \mathrm{SD} \mu \mathrm{g} / \mathrm{ml})$ of garden sage essence and BHT in various models

\begin{tabular}{cccc}
\hline Experiment & DPPH* & BCP & b \\
\hline Garden sage & $907.7 \pm 5.3 \mathrm{~b}$ & $454.2 \pm 5.8 \mathrm{~b}$ & $1362.42 \pm 1.4 \mathrm{~b}$ \\
BHT & $12.9 \pm 1.7 \mathrm{a}$ & $62.9 \pm 1.6 \mathrm{a}$ & $61.6 \pm 0.9 \mathrm{a}$ \\
\hline *DPPH: radical scavenging potential, BCB: linoleic acid inhibition potential, RP: reduction potential
\end{tabular}

\section{B) Study of DMBA-Induced Cancer Groups Receiving Garden Sage Aqueous Extract}

Breast tissue changes in cancer-bearing rats were compared in both groups (treated with distilled water and garden sage aqueous extract).

Lobules were counted using light microscopy.

T-test statistical analysis was also exploited to evaluate the changes. The results indicated a reduction in the number of lobules in the group receiving garden sage aqueous extract, and this reduction was statistically significant in the $4^{\text {th }}$ and $6^{\text {th }}$ months.

Table 2. The lobule count in the breast tissue cancer-bearing rats which received garden sage and distilled water

\begin{tabular}{cll}
\hline Number of lobules & Group & \\
\hline $1.43 \pm 1.53$ & 4 months & Control \\
$2.01 \pm 2.30$ & 5 months & \\
$4.30 \pm 1.73$ & 6 months & \\
$0.081 \pm 0.40$ & $4 *$ months & \\
$1.50 \pm 1.90$ & 5 months & Treated with garden sage \\
$0.99 \pm 0.87$ & $6 *$ months &
\end{tabular}

* Indicative of significant difference with the control group $(\mathrm{p}<0.05)$

\subsection{Discussion}

\section{Total Phenolic Content and Antioxidant Activity}

Total phenolic content is an indicator of the antioxidant capacity of the plant. Garden sage possesses higher phenolic content in comparison with many other medicinal herbs including Chamomile, Pot marigold, Rhubarb, and Lavender [11]. Garden sage essence also contains $~ 60 \%$ oxygen-bearing monotropins and about $20 \%$ oxygen-bearing hydrocarbons. Among the most prominent compounds of these groups, alpha-thujene, camphor, viridiflorol, borneol, 1,8-cineol, beta-thujene, and bornyl acetate can be mentioned whose contents vary depending on the circumstances. Therefore, these groups may exhibit distinct antioxidant potential in different conditions [12].

Viado-Martos et al. [6] reported the total phenolic content of garden sage essence as $98.122 \mathrm{mg}$ galic acid per liter of sample.

Estrogenic compounds initiate the breast growth and lactation system and account for breast development in adult females.

The phytoestrogens are structurally and functionally similar to 17-beta-sterol. They include several chemical groups among which isoflavonoid can be mentioned [13]. 
Phytoestrogens display estrogen-compatible effects at low blood estrogen concentrations. In contrast, they behave oppositely at high estrogen levels [14].

Phytoestrogen estrogenic activity is concentration-dependent [15]. At low concentrations, phytoestrogens induce growth and reproduction of breast tissues similar to estrogens, while at high concentrations, they prevent excessive growth and proliferation of breast tissues and DNA synthesis [16].

Garden sage contains genitein phytoestrogen [17].

Findings demonstrated that DMBA impact on breast tissue is similar to that of estrogen, and it increased the number of lobules in rat's breast tissue.

However, rats treated by garden sage aqueous extract did not exhibit similar results. Garden sage extract led to the reduction of lobule counts in the breast tissue of DMBA-induced cancerous rats when compared with the group treated by DMBA and water. Such an effective therapeutic impact can be attributed to phytoestrogens present in the garden sage herb.

\section{Conclusion}

Angiogenesis is a key process in cancer spread and metastasis. The hydroalcoholic extract of garden sage halted angiogenesis in the breast cell line of both human and mouse models; the highest impact was observed in hexane extract. Findings indicated the therapeutic effects of garden sage (i.e. its in vitro anti-angiogenesis activity and anti-migratory properties). Saliva officinalis can potentially prevent breast cancer.

\section{Nomenclature}

DMBA: Dimethyl-benzanthracene

DPPH: 2,2-diphenyl-1-picrylhydrazyl used to assess the radical scavenging potential of the substances. It is a darkcolored crystalline powder composed of stable free-radical molecules.

$B C B$ : Linoleic acid inhibition potential.

$R P$ : Reduction potential.

\section{Declaration of Competing Interest}

The authors declare that they have no known competing financial interests or personal relationships that could have appeared to influence the work reported in this paper.

\section{References}

[1] Jedinák, A., Mučková, M., Košt’álová, D., Maliar, T., \& Mašterová, I. (2006). Antiprotease and Antimetastatic Activity of Ursolic Acid Isolated from Salvia officinalis. Zeitschrift Für Naturforschung C, 61(11-12), 777-782. doi:10.1515/znc-2006-11-1203.

[2] El Hadri, A., del Rio, M. G., Sanz, J., Coloma, A. G., Idaomar, M., Ozonas, B. R., ... \& Reus, M. I. S. (2010). Cytotoxic activity of $\alpha$-humulene and transcaryophyllene from Salvia officinalis in animal and human tumor cells. An R Acad Nac Farm, 76(3), 343-356.

[3] Bradley, P. (Ed.). (2006). British herbal compendium: a handbook of scientific information on widely used plant drugs. British Herbal Medicine Assoc.

[4] Miata M, Furukawa M, Takhashi K. (2001) Mechanism of dimethylbenzantrencen-induced immune -toxicity:role of metabolic activation at the target organ. Pharmacology. (86):302-309.

[5] Motoyama, J., Yamashita, N., Morino, T., Tanaka, M., Kobayashi, T., \& Honda, H. (2008). Hyperthermic treatment of DMBAinduced rat mammary cancer using magnetic nanoparticles. BioMagnetic Research and Technology, 6(1), 2. doi:10.1186/1477$044 x-6-2$.

[6] Viuda-Martos, M., Mohamady, M. A., Fernández-López, J., Abd ElRazik, K. A., Omer, E. A., Pérez-Alvarez, J. A., \& Sendra, E. (2011). In vitro antioxidant and antibacterial activities of essentials oils obtained from Egyptian aromatic plants. Food Control, 22(11), 1715-1722. doi:10.1016/j.foodcont.2011.04.003.

[7] Ebrahimabadi, A. H., Mazoochi, A., Kashi, F. J., Djafari-Bidgoli, Z., \& Batooli, H. (2010). Essential oil composition and antioxidant and antimicrobial properties of the aerial parts of Salvia eremophila Boiss. From Iran. Food and Chemical Toxicology, 48(5), 1371-1376. doi:10.1016/j.fct.2010.03.003.

[8] Kulisic, T., Radonic, A., Katalinic, V., \& Milos, M. (2004). Use of different methods for testing antioxidative activity of oregano essential oil. Food Chemistry, 85(4), 633-640. doi:10.1016/j.foodchem.2003.07.024. 
[9] Kar, A., Panda, S., \& Bharti, S. (2002). Relative efficacy of three medicinal plant extracts in the alteration of thyroid hormone concentrations in male mice. Journal of Ethnopharmacology, 81(2), 281-285. doi:10.1016/s0378-8741(02)00048-x.

[10] AOCS names official referee chemists: 1976-77. (1976). Journal of the American Oil Chemists' Society, 53(7), 426A-427A. doi:10.1007/bf02636806.

[11] Miliauskas, G., Venskutonis, P. R., \& van Beek, T. A. (2004). Screening of radical scavenging activity of some medicinal and aromatic plant extracts. Food Chemistry, 85(2), 231-237. doi:10.1016/j.foodchem.2003.05.007.

[12] Tel, G., Öztürk, M., Duru, M. E., Harmandar, M., \& Topçu, G. (2010). Chemical composition of the essential oil and hexane extract of Salvia chionantha and their antioxidant and anticholinesterase activities. Food and Chemical Toxicology, 48(11), 3189-3193. doi:10.1016/j.fct.2010.08.020.

[13] Adlercreutz, H., Bannwart, C., Wähälä, K., Mäkelä, T., Brunow, G., Hase, T., ... Vickery, L. E. (1993). Inhibition of human aromatase by mammalian lignans and isoflavonoid phytoestrogens. The Journal of Steroid Biochemistry and Molecular Biology, 44(2), 147-153. doi:10.1016/0960-0760(93)90022-o.

[14] Kurzer, M. S., \& Xia, X. (1997). Dietary Phytoestrogens Annu Rev Nutr. 17, 353-381.

[15] Maggiolini, M., Bonofiglio, D., Marsico, S., Panno, M. L., Cenni, B., Picard, D., \& Andò, S. (2001). Estrogen receptor $\alpha$ mediates the proliferative but not the cytotoxic dose-dependent effects of two major phytoestrogens on human breast cancer cells. Molecular pharmacology, 60(3), 595-602.

[16] Van der Woude, H., ter Veld, M. G. R., Jacobs, N., van der Saag, P. T., Murk, A. J., \& Rietjens, I. M. C. M. (2005). The stimulation of cell proliferation by quercetin is mediated by the estrogen receptor. Molecular Nutrition \& Food Research, 49(8), 763-771. doi:10.1002/mnfr.200500036.

[17] Mueller, S. O., Clark, J. A., Myers, P. H., \& Korach, K. S. (2002). Mammary Gland Development in Adult Mice Requires Epithelial and Stromal Estrogen Receptor $\alpha$. Endocrinology, 143(6), 2357-2365. doi:10.1210/endo.143.6.8836. 